\title{
Socio-economic Aspects of Health-Related Behaviors and Their Dynamics: A Case Study for the Netherlands
}

\author{
Reza Rezayatmand ${ }^{1,2, *}$, Milena Pavlova ${ }^{2}$, Wim Groot ${ }^{2,3}$
}

\begin{abstract}
Background: Previous studies have mostly focused on socio-demographic and health-related determinants of health-related behaviors. Although comprehensive health insurance coverage could discourage individual lifestyle improvement due to the ex-ante moral hazard problem, few studies have examined such effects. This study examines the association of a comprehensive set of factors including socio-demographic, health status, health insurance, and perceived change in health insurance coverage with health-related behaviors and their dynamics (ie, changes in behavior). Methods: Using Survey of Health, Aging, and Retirement in Europe (SHARE) data (a European aging survey among 50+ years old) for the Netherlands in 2004 and 2007 (sample size: 1745), binary and multinomial logit models are employed to study health-related behaviors (daily smoking, excessive alcohol use, and physical inactivity in 2004) and their corresponding changes (stopping or starting unhealthy behavior between 2004 and 2007).

Results: Our findings show that being older, being female, having higher education and living with a partner increase the likelihood not to be a daily smoker or to stop daily smoking. At the same time, being older $(\mathrm{OR}=3.02[1.31,6.95])$ and being female $(\mathrm{OR}=1.77[1.05,2.96])$ increases the likelihood to be or to become physically inactive. We also find that worse perceived health insurance coverage in 2007 is associated with a lower likelihood $(\mathrm{OR}=0.19$ [0.06, 0.57]) of stopping excessive alcohol use in that year. However, we do not find a strong association between the type of health insurance and health behavior.

Conclusion: Our findings show that all above mentioned factors (ie, socio-demographic and health status factors) are associated with health-related behavior but not in a consistent way across all behaviors. Moreover, the dynamics of each behavior (positive or negative change) is not necessarily determined by the same factors that determine the state of that behavior. We also find that better perceived health insurance coverage is associated with a healthier lifestyle which is not compatible with an ex-ante moral hazard interpretation. Our results provide input to target policies towards elderly individuals in need of lifestyle change. However, further research should be done to identify the causal effect of health insurance on health-related behavior.

Keywords: Health Insurance, Health-Related Behavior, Healthier Lifestyle, The Netherlands, Ex-ante Moral Hazard

Copyright: @ 2016 by Kerman University of Medical Sciences

Citation: Rezayatmand R, Pavlova M, Groot W. Socio-economic aspects of health-related behaviors and their dynamics: a case study for the Netherlands. Int J Health Policy Manag. 2016;5(4):237-251. doi:10.15171/ijhpm.2015.212
\end{abstract}

\section{Article History:}

Received: 7 May 2015

Accepted: 19 December 2015

ePublished: 31 December 2015

\section{*Correspondence to:}

Reza Rezayatmand

Email: mr.rezayatmand@maastrichtuniversity.nl

\section{Key Messages}

Implications for policy makers

- Health-related behavior should not be treated as a uniform concept, each behavior should rather be considered separately.

- The dynamics of health-related behavior are not necessarily associated with the same factors that determine the state of that behavior.

- A comprehensive understanding of the determinants of health-related behavior is crucial to change individuals' behaviors into a healthier lifestyle.

- Ex-ante moral hazard does not seem to undermine healthy behavior.

Implications for public

Although some studies have found that someone who smokes is more likely also to drink excessively and be physically inactive, in this study, we found that different people engage in different unhealthy behaviors. Additionally, those more likely to desist from such behaviors also vary. Therefore, we recommend that researchers and policy-makers should consider each health behavior separately.

Some people have argued that people should pay privately for their healthcare because people will only look after their health if they have to pay when something goes wrong with their health. Our study found that in the Netherlands, this is not the case: people who received more coverage from their health insurer looked after their health more. 


\section{Background}

Lifestyle change is an important goal of public health policy. The role of unhealthy behavior (ie, smoking, excessive alcohol use, physical inactivity) in acquiring non-communicable diseases (ie, diabetes, cancer, cardiovascular disease) has been clearly documented. ${ }^{1}$ In addition, evidence points to a high worldwide prevalence of unhealthy behavior. ${ }^{1,2}$ This has brought policy-makers to agree on the urgent need for individual lifestyle change. ${ }^{3}$ Thus, it is important to have a better understanding of the factors that determine individuals' choices of unhealthy behaviors and their decisions to change those behaviors.

Prior research has documented that an unhealthy lifestyle is related to socio-demographic and health status factors. ${ }^{4-8}$ For instance, it has been shown that age, gender, marital status, and income determine the prevalence of unhealthy behaviors., ${ }^{4,-17}$ Some studies also show that self-perceived health is associated with those behaviors. ${ }^{6,18}$ Insurance coverage could also discourage individual lifestyle improvement and prevention activities, which is known as the ex-ante moral hazard problem. ${ }^{19}$ According to the health insurance model, ex-ante moral hazard is defined as the possibility that the insurance for curative care discourages primary prevention on the side of the insured. ${ }^{20}$ Few studies have actually investigated the role of health insurance in health-related behaviors and their changes. ${ }^{21}$ In addition, previous studies have mostly focused on only one type of unhealthy behavior, ${ }^{9,22-25}$ while it is helpful to find out whether the effect of variables are consistent across different health-related behaviors. This helps to see to what extent health behaviors can be considered as one concept or behavior-specific actions are needed. Thus, our main objective is to build up a comprehensive model, to our knowledge for the first time including health insurance variables, associated with the individual's choice of unhealthy behavior and the decision to change those behaviors.

For this analysis, we use Dutch data from the first and the second wave of the Survey on Health, Aging, and Retirement in Europe (SHARE Release 2.5.0) which were collected in 2004 and 2007 (coincidently this was before and after the health insurance reform in the Netherlands). Thus, it enables us to enter health insurance variables in our general analysis of health-related behavior, making the model as comprehensive as possible.

Having introduced the health insurance reform in 2006, a universal compulsory health insurance coverage replaced the former public and private health insurance systems. Before the reform, individuals with a gross individual annual income up to a ceiling set by the government were entitled to the compulsory social insurance and those with a higher individual income had to buy the voluntary private health insurance. ${ }^{26}$ The fact that the reform took place suggests that the insurance coverage for some individuals might have changed. For example, as the new system is mandatory for everyone, a better insurance coverage is expected for those who had voluntary private insurance. Thus, we are able to analyze how this change is associated with the dynamics of health-related behaviors between 2004 and 2007. At the same time, it is assumed that, in 2004, social health insurance has provided a more generous coverage than private health insurance. ${ }^{27}$ Thus, we are also able to analyze how the type of health insurance is associated with the state of health-related behavior in that year. We explore whether the results are consistent with ex-ante moral hazard.

Our contribution to the literature is three-fold. First, with previous studies in mind, we define a comprehensive set of factors which includes socio-demographic, health status, health insurance and perceived change in health insurance coverage. Second, the same set of factors is exploited to predict three common types of health-related behaviors, daily smoking, alcohol consumption, and physical inactivity. This gives us the possibility to identify whether and to what extent the effects of explanatory variables are consistent among different behaviors. The third contribution is that, besides behavior per se, we also study positive and negative changes in behavior, which provides more insight into the dynamics and consistency of the effect of each factor. As a result, this study aims to examine the association of the above-mentioned factors with health-related behavior and their dynamics. Specifically the study explores the consistency of the effect of these factors across different types of behavior as well as across the dynamics of each type of behavior.

\section{Methods}

Data and Study Sample

The SHARE is a multidisciplinary and cross-national panel database of micro data on health, socio-economic status as well as social and family networks which is based on nationally representative samples of the non-institutionalized population aged 50 years and older in Europe. The SHARE baseline study has been conducted in 11 countries in 2004/2005, followed by second wave in 2006/2007 and a fourth wave in 2011/2012 in 14 and 19 countries, respectively. In 2008, the third wave of survey, SHARELIFE, was performed to collect detailed retrospective life histories in 13 countries. ${ }^{28}$ The SHARE dataset is publicly and freely available.

In the Netherlands, the first and the second wave of the SHARE have been performed in 2004 and 2007. The first SHARE wave comprises a sample size of 2979 individuals (household response rate of $61.6 \%$ and individual [within household] response rate of $87.8 \%) .{ }^{29}$ The total sample in the second wave includes 2661 individuals, while the longitudinal sample consists of 1777 participants. The attrition analysis that we carried out shows no selective dropout from the sample in terms of gender or annual household gross income. However, it shows that those who remain in the sample compared to those who drop out are on average relatively younger (age 62.52 versus $63.94, P=0.0001$ ), have lower education level (international standard classification of education, ISCED) and are more likely to live with a partner. Attrition analysis carried out by the SHARE ${ }^{30}$ does not show clear cut results for demographic variables that predict the attrition rate. In total, 1745 out of 1777 individuals in longitudinal sample answered all questions corresponding to three health-related behaviors in both years (2004 and 2007). This particular set of individuals forms the sample for analysis in this study. Because the fourth wave of SHARE has not provided information about the type of insurance, we could not include this wave in the present analysis. A more detailed description of the Dutch SHARE dataset, its methods, sampling frame, and respondents is provided elsewhere. ${ }^{31}$ 


\section{Indicators of Unhealthy Behavior}

SHARE devoted a section of the questionnaire on healthrelated behaviors where respondents were asked about smoking, alcohol consumption, and the level of physical activity. The measures used in the present analysis are as follows:

Smoking: Individuals are asked if they have ever smoked daily for a period of at least one year. Those who reply affirmatively are asked whether or not they are current smokers. Respondents who answer "yes" to both questions are classified as current daily smoker.

Excessive alcohol use: Participants are asked about the frequency of drinking more than two glasses of beer, wine, or hard liquors (ie, almost every day, 5 or 6 days a week, 3 or 4 days a week, once or twice a month, less than once a month, and not at all in the last 6 months). We use the constructed dummy variable by SHARE comprising information of those who choose the options of almost every day or five/six days a week. This variable is the closest approximation to more than the recommended level of drinking available in SHARE.

Physical inactivity: Individuals are asked how often they engage in vigorous activity (ie, sport, heavy housework, or a job that requires physical labor) or moderate activity (ie, activities requiring a low or moderate level of energy such as gardening, cleaning the car, or walking) with the following response options: more than once a week, once a week, one to three times a month, or hardly ever, or never. A dummy variable constructed by SHARE is used which describes physically inactive individuals as those who never or almost never engage in moderate or vigorous physical activity.

Behavior change: Health-related behavior of an individual is compared between 2004 and 2007. Consequently, we create six variables of interest to indicate the behavior changes over the time: three dummy variables that indicate a positive change (ie, for those engaged in unhealthy behavior in 2004); and three dummy variables that indicate a negative change (ie, for those who did not engage in unhealthy behavior in 2004). As a result, we are able to run separate models for positive and negative change to distinguish between positive no change (continuing healthy behavior) and negative no change (continuing unhealthy behavior). For instance, in the positive change model, we compare those who stop smoking with current smokers, while in the negative change model we compare those who start smoking with never smokers.

\section{Explanatory Variables}

The following groups of explanatory variables are included in the models.

Demographics: For age, we create dummies to indicate four age categories (ie, aged 55 or under, 56-64, 65-74, and 75 or older). We define these age categories considering that the majority of our respondents are aged 55 or older, and also that the retirement age in the Netherlands is 65 years. The marital status is classified into two categories of living with or without spouse or partner. For all variables, the value for 2004 is used.

Socio-economic status: Individuals' educational levels are classified into four groups based on the ISCED-97 used by SHARE. Details about ISCED-97 scale can be found in Appendix 1. We also use quintiles of annual household gross income in our analysis. For these variables, the value for 2004 is used.

Health status: As a proxy for health condition in 2004, we use a self-rated question, ranking individuals' self-perceived health status from poor to excellent. At the same time, a question on activity limitation because of a health problem (the so-called Global Activity Limitation Index [GALI ${ }^{32}$ ) is included. Using the health indicators of two years, we create dummies for a worse or a better condition in 2007 compared to 2004 .

For a more straightforward interpretation of the results, we enter 'education,' 'annual gross household income quintile, and 'self-perceived health' as continuous variables in the models. However, we also ran regressions for each model while treating them as categorical explanatory variables.

Health insurance coverage: To indicate the individuals' health insurance status at the baseline (2004), we create dummies for having 'voluntary private insurance', having 'social insurance' or having 'no insurance.' In addition, the variable indicating individuals' health insurance deductible is added. As mentioned earlier it is expected that the type of health insurance in 2004 depends on the level of income, thus we also add the interaction between annual household gross income quintile and the type of insurance in our models. The preliminary analysis showed that including interaction terms increased the explanatory power of the models. It should be added that the eligibility criteria for the type of insurance do not depend on age. In the second wave, respondents are asked to evaluate their current health insurance coverage (as compared to what they had in the first wave) whether there is a worse or a better coverage, or no change. We take this variable as an indicator of the perceived change in health insurance status. As health insurance reform has happened in the middle of two waves of SHARE data collection, it is supposed that those variables could be influenced by health insurance reform. A more detailed description of all variables used in the present analysis is provided in Appendix 1.

\section{Analysis}

A binary logistic regression is used to estimate base models in 2004 as well as change models for 2004-2007. The set of explanatory variables used for the change models is slightly different from the base models. The change models include more explanatory variables which indicate positive or negative changes in health status and health insurance coverage in 2007. These models also include a dummy variable indicating a change in marital status between 2004 and 2007. However, due to a lack of data, we could not specify the direction of the change in marital status (if a partner is acquired or lost). In addition, these models only include a dummy for voluntary private insurance. The reason for not including the dummy variable of "no insurance" is the low number of observations. In fact, running a separate model for positive and negative change enables us to compare each change group with its corresponding no-change group (ie, those who continue unhealthy behavior for positive change and those who continue healthy behavior for negative change), while this is not possible in a multinominal approach. However, in order to get more insight into the dynamics of health-related behaviors, we also run a multinominal logistic regression with four options (ie, continue unhealthy behavior, positive 
change, continue healthy behavior - base category, and negative change) while comparing all options with those who continue their healthy behavior in 2007. For all independent variables, the variance inflation factor (VIF) is less than 1.5 which is acceptable. The analysis is carried out using STATA version 11 .

\section{Results}

Descriptive Statistics

As Table 1 shows, in 2004 (the baseline year), the prevalence of daily smoking, excessive alcohol use and physical inactivity was $24 \%, 18 \%$, and $4 \%$, respectively. Regarding health insurance status, $60 \%$ of respondents had compulsory social insurance and $36 \%$ had a voluntary private insurance, while
$4 \%$ had no insurance. In $2007,19 \%$ of daily smokers stopped daily smoking, while $3 \%$ of non-daily smokers started doing so; $63 \%$ of excessive alcohol users stopped excessive drinking, while $4 \%$ of non-excessive alcohol users started excessive drinking and, 58\% of physically inactive individuals stopped physical inactivity, while $6 \%$ of physically active respondents started physical inactivity. As the new universal health insurance coverage has been introduced on the first of January 2006, in 2007 everyone was obliged to be insured under the new system. However, when individuals are asked to compare their health insurance coverage between 2004 and $2007,11 \%$ of respondents state that they had better health insurance coverage, while $8 \%$ report the contrary. Given the age specification of the SHARE dataset, our results refer to

Table 1. Descriptive Statistics

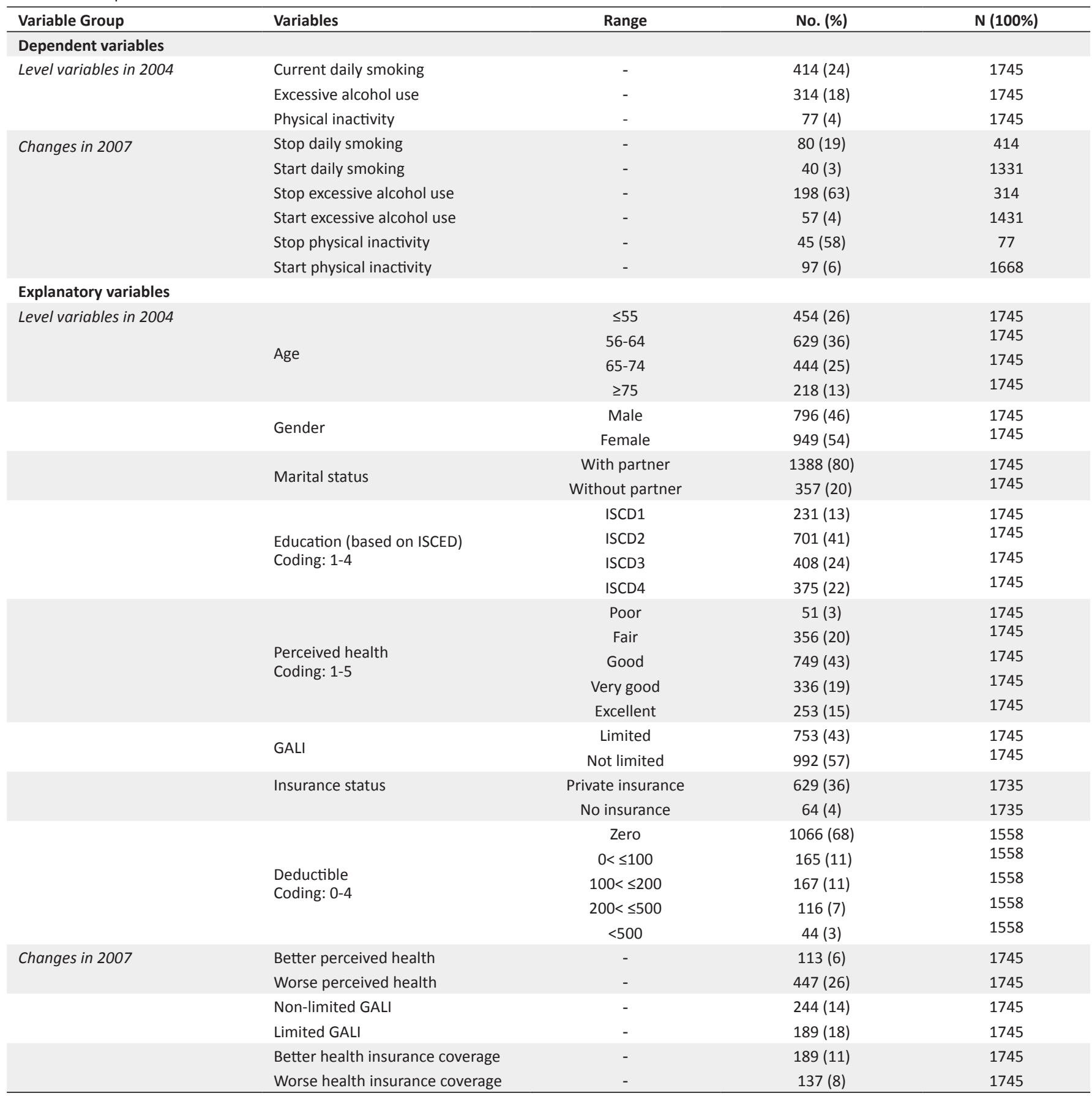

Abbreviations: ISCED, International Standard Classification of Education; GALI, Global Activity Limitation Index. 
people aged 50 and over.

Regression Results

Tables 2, 3, and 4 show the regression results for our base models in 2004, as well as for positive and negative change models between 2004 and 2007, respectively. All regression models are statistically significant (see the models' chi-square in the tables) except the one for a positive change in physical inactivity. For this non-significant model, we present the best specification we could obtain.

As previously noted, we also ran regressions for each model while treating "education," "annual gross household income quintile," and "self-perceived health" as categorical explanatory variables but because this did not change the results, we keep the models as presented in the tables. Apart from that, we used the likelihood ratio test to see whether or not analysis should be stratified based on gender. However, the test did not show statistically significant results for daily smoking and excessive alcohol use. In case of physical inactivity, a gender-stratified analysis was not possible because of the very low number of observations per gender. In addition, as a robustness check we separated out those with limitations on activity (GALI) in the regression of physical inactivity (our base model in 2004) but the results did not significantly change. Doing the same was not possible in case of positive change in physical activity in 2007 because of an insufficient number of observations. However, while leaving those with limitation on activity out from the model of negative change in physical activity (2007), the effect of age and gender on starting physical inactivity disappeared. Thus, the effect of age and gender on becoming physically inactive in 2007 (as reported in Table 4) seems to be mostly driven by those who have limitation on activity. Below, the regression results are summarized based on the explanatory variables.

Socio-demographic and Socio-economic Variables

The influence of socio-demographic variables on health behaviors can be summarized as follows based on the logistic regression results.

Age: Table 2 shows that in 2004, those who are in the oldest age category (age $\geq 75$ ) have the lowest likelihood of daily smoking $(\mathrm{OR}=0.25[0.25,0.41])$. Those aged 75 or older are, however, considerably more likely to be physically inactive $(\mathrm{OR}=4.48$ $[1.86,10.83])$ in 2004 (Table 2) or become physically inactive $(\mathrm{OR}=3.02[1.31,6.95])$ in 2007 (Table 4).

Gender: As depicted in Table 2, women are less likely than men to smoke daily $(\mathrm{OR}=0.74[0.58,0.95])$ and to excessively use alcohol $(\mathrm{OR}=0.55[0.41,0.73])$. The results of the change

Table 2. Health-Related Behavior in 2004 (Logit Estimates)

\begin{tabular}{|c|c|c|c|c|c|c|}
\hline & \multicolumn{2}{|c|}{ Daily Smoking } & \multicolumn{2}{|c|}{ Excessive Alcohol Use } & \multicolumn{2}{|c|}{ Physical Inactivity } \\
\hline & OR & $95 \% \mathrm{Cl}$ & OR & $95 \% \mathrm{Cl}$ & OR & $95 \% \mathrm{Cl}$ \\
\hline \multicolumn{7}{|l|}{ Explanatory variables } \\
\hline Age $\leq 55$ & 1.00 & - & 1.00 & - & 1.00 & - \\
\hline Age 56-64 & $0.75^{\mathrm{a}}$ & {$[0.56,1.01]$} & $1.36^{\mathrm{a}}$ & {$[0.97,1.91]$} & 1.12 & {$[0.46,2.68]$} \\
\hline Age 65-74 & $0.43^{c}$ & {$[0.30,0.61]$} & 1.03 & {$[0.69,1.54]$} & 2.05 & {$[0.87,4.86]$} \\
\hline Age $\geq 75$ & $0.25^{c}$ & {$[0.15,0.41]$} & 0.68 & {$[0.39,1.17]$} & $4.48^{c}$ & {$[1.86,10.83]$} \\
\hline Male & 1.00 & - & 1.00 & - & 1.00 & - \\
\hline Female & $0.74^{\mathrm{b}}$ & {$[0.58,0.95]$} & $0.55^{c}$ & {$[0.41,0.73]$} & 1.59 & {$[0.90,2.81]$} \\
\hline Living without partner & 1.00 & - & 1.00 & - & 1.00 & - \\
\hline Living with partner & $0.74^{a}$ & {$[0.54,1.02]$} & 1.25 & {$[0.84,1.87]$} & 1.11 & {$[0.58,2.12]$} \\
\hline Education $^{d}$ & $0.82^{\mathrm{c}}$ & {$[0.71,0.95]$} & 1.09 & {$[0.93,1.28]$} & 1.03 & {$[0.73,1.44]$} \\
\hline Annual HH gross income quintile ${ }^{d}$ & 1.01 & {$[0.90,1.14]$} & 1.05 & {$[0.91,1.21]$} & 0.99 & {$[0.76,1.29]$} \\
\hline Perceived health ${ }^{d}$ & $0.79^{c}$ & {$[0.69,0.91]$} & 1.07 & {$[0.92,1.25]$} & $0.32^{\mathrm{c}}$ & {$[0.22,0.47]$} \\
\hline GALI, not-limited & 1.00 & - & 1.00 & - & 1.00 & - \\
\hline GALI, limited & $0.68^{c}$ & {$[0.51,0.90]$} & 0.86 & {$[0.63,1.18]$} & 0.80 & {$[0.42,1.52]$} \\
\hline Health insurance deductible $^{d}$ & 0.95 & {$[0.83,1.09]$} & 1.00 & {$[0.87,1.15]$} & 0.90 & {$[0.62,1.29]$} \\
\hline Social insurance & 1.00 & - & 1.00 & - & 1.00 & - \\
\hline Private insurance & $0.34^{\mathrm{b}}$ & {$[0.15,0.77]$} & 0.49 & {$[0.20,1.17]$} & 1.59 & {$[0.35,7.19]$} \\
\hline No insurance & 1.59 & {$[0.25,10.08]$} & 0.75 & {$[0.11,4.87]$} & 0.07 & {$[0.00,430.57]$} \\
\hline \multicolumn{7}{|l|}{ Interaction } \\
\hline $\mathrm{HH}$ income quintile * Private insurance & $1.24^{\mathrm{a}}$ & {$[1.00,1.54]$} & $1.28^{\mathrm{b}}$ & {$[1.02,1.61]$} & 0.85 & {$[0.54,1.35]$} \\
\hline $\mathrm{HH}$ income quintile * NO insurance & 0.75 & {$[0.44,1.28]$} & 1.27 & {$[0.77,2.10]$} & 1.73 & {$[0.21,14.24]$} \\
\hline \multirow[t]{2}{*}{ Other model specification } & \multicolumn{2}{|c|}{ Pseudo R2 .050 } & \multicolumn{2}{|c|}{ Pseudo R2 .053 } & \multicolumn{2}{|c|}{ Pseudo R2 .159 } \\
\hline & \multicolumn{2}{|c|}{ Model $\chi^{2}(14)^{c} 86.09$} & \multicolumn{2}{|c|}{ Model $\chi^{2}(14)^{c} 76.71$} & \multicolumn{2}{|c|}{ Model $\chi^{2}(14)^{c} 83.83$} \\
\hline $\mathrm{N}$ (included in analysis) & \multicolumn{2}{|c|}{1533} & \multicolumn{2}{|c|}{1533} & \multicolumn{2}{|c|}{1533} \\
\hline
\end{tabular}

Abbreviation: GALI, Global Activity Limitation Index.

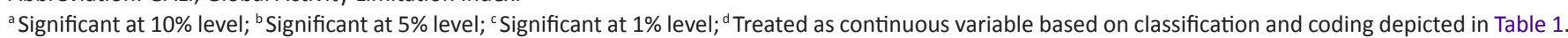


Table 3. Positive Change in Health-Related Behavior in 2007 (Logit Estimates)

\begin{tabular}{|c|c|c|c|c|c|c|}
\hline & \multicolumn{2}{|c|}{ Stop Daily Smoking } & \multicolumn{2}{|c|}{ Stop Excessive Alcohol Use } & \multicolumn{2}{|c|}{ Stop Physical Inactivity } \\
\hline & OR & $95 \% \mathrm{Cl}$ & OR & $95 \% \mathrm{Cl}$ & OR & $95 \% \mathrm{Cl}$ \\
\hline \multicolumn{7}{|l|}{ Explanatory variables } \\
\hline Age $\leq 55$ & 1.00 & - & 1.00 & - & 1.00 & - \\
\hline Age $56-64$ & 1.78 & {$[0.88,3.58]$} & 1.24 & {$[0.61,2.51]$} & 0.28 & {$[0.01,6.11]$} \\
\hline Age 65-74 & 1.45 & {$[0.61,3.43]$} & 1.00 & {$[0.43,2.31]$} & $21.67^{\mathrm{a}}$ & {$[0.69,678.13]$} \\
\hline Age $\geq 75$ & 0.28 & {$[0.03,2.35]$} & 1.11 & {$[0.36,3.43]$} & 11.95 & {$[0.39,369.78]$} \\
\hline Male & 1.00 & - & 1.00 & - & 1.00 & - \\
\hline Female & $0.60^{\mathrm{a}}$ & {$[0.33,1.10]$} & $2.57^{c}$ & {$[1.40,4.70]$} & 1.28 & {$[0.25,6.61]$} \\
\hline Living without partner & 1.00 & - & 1.00 & - & 1.00 & - \\
\hline Living with partner & $3.71^{\mathrm{b}}$ & {$[1.31,10.52]$} & 0.71 & {$[0.30,1.67]$} & $9.65^{b}$ & {$[1.22,76.43]$} \\
\hline Education $^{d}$ & 1.10 & {$[0.78,1.55]$} & 0.95 & {$[0.68,1.34]$} & 1.32 & {$[0.48,3.61]$} \\
\hline Annual HH gross income quintile ${ }^{d}$ & 1.08 & {$[0.82,1.43]$} & 1.00 & {$[0.74,1.36]$} & 0.88 & {$[0.35,2.20]$} \\
\hline Perceived health ${ }^{d}$ & $1.44^{\mathrm{b}}$ & {$[1.02,2.04]$} & $1.36^{\mathrm{a}}$ & {$[1.00,1.85]$} & 0.56 & {$[0.16,1.94]$} \\
\hline GALI, not-limited & 1.00 & - & 1.00 & - & 1.00 & - \\
\hline GALI, limited & 0.74 & {$[0.31,1.76]$} & 0.81 & {$[0.36,1.86]$} & 0.13 & {$[0.00,5.54]$} \\
\hline Health insurance deductible ${ }^{d}$ & $1.40^{\mathrm{b}}$ & {$[1.02,1.92]$} & 1.13 & {$[0.84,1.52]$} & $0.40^{\mathrm{a}}$ & {$[0.15,1.10]$} \\
\hline Social insurance & 1.00 & - & 1.00 & - & 1.00 & - \\
\hline Private insurance & 0.47 & {$[0.05,4.18]$} & $0.08^{c}$ & {$[0.01,0.50]$} & 0.09 & {$[0.00,16.17]$} \\
\hline \multicolumn{7}{|l|}{ Change in 2007} \\
\hline Same or worse perceived health & 1.00 & - & 1.00 & - & 1.00 & - \\
\hline Better perceived health & 2.53 & {$[0.60,10.60]$} & 0.77 & {$[0.25,2.39]$} & - & - \\
\hline Same or better perceived health & 1.00 & - & 1.00 & - & 1.00 & - \\
\hline Worse perceived health & $3.96^{\mathrm{c}}$ & {$[1.90,8.23]$} & 1.70 & {$[0.84,3.43]$} & $0.07^{\mathrm{b}}$ & {$[0.01,0.64]$} \\
\hline No change in limited GALI & 1.00 & - & 1.00 & - & 1.00 & - \\
\hline Non-limited GALI & $2.44^{\mathrm{a}}$ & {$[0.89,6.73]$} & 1.00 & {$[0.38,2.60]$} & 2.04 & {$[0.12,33.68]$} \\
\hline No change in non-limited GALI & 1.00 & - & 1.00 & - & 1.00 & - \\
\hline Limited GALI & 0.75 & {$[0.33,1.72]$} & 0.88 & {$[0.43,1.80]$} & 0.27 & {$[0.01,6.02]$} \\
\hline Same or worse health insurance coverage & 1.00 & - & 1.00 & - & 1.00 & - \\
\hline Better health insurance coverage & 0.46 & {$[0.14,1.52]$} & $2.61^{\mathrm{a}}$ & {$[0.97,7.05]$} & $49.52^{\mathrm{a}}$ & {$[0.90,2716.75]$} \\
\hline Same or better health insurance coverage & 1.00 & - & 1.00 & - & 1.00 & - \\
\hline Worse health insurance coverage & 0.98 & {$[0.32,2.99]$} & $0.19^{c}$ & {$[0.06,0.57]$} & - & - \\
\hline \multicolumn{7}{|l|}{ Interaction } \\
\hline $\mathrm{HH}$ income quintile* Private insurance & 1.09 & {$[0.63,1.86]$} & $1.69^{b}$ & {$[1.05,2.70]$} & 1.40 & {$[0.36,5.48]$} \\
\hline \multirow[t]{2}{*}{ Other model specification } & \multicolumn{2}{|c|}{ Pseudo R2 .125 } & \multicolumn{2}{|c|}{ Pseudo R2 .107 } & \multicolumn{2}{|c|}{ Pseudo R2 .344 } \\
\hline & \multicolumn{2}{|c|}{ Model $\chi 2(18)^{c} 43.39$} & \multicolumn{2}{|c|}{ Model $\chi 2(18)^{c} \quad 38.57$} & \multicolumn{2}{|c|}{ Model $\chi 2(18)^{a} \quad 26.46$} \\
\hline $\mathrm{N}$ (included in analysis) & \multicolumn{2}{|c|}{361} & \multicolumn{2}{|c|}{272} & \multicolumn{2}{|c|}{57} \\
\hline
\end{tabular}

Abbreviation: GALI, Global Activity Limitation Index.

a Significant at $10 \%$ level; ${ }^{\text {b }}$ Significant at $5 \%$ level; ${ }^{\mathrm{c}}$ Significant at $1 \%$ level; ${ }^{\mathrm{d}}$ Treated as continuous variable based on classification and coding depicted in Table 1. The age groups are compared to age $\leq 55$.

models 2004-2007 (Tables 3 and 4) also show that being a female rather than a male considerably increases the odds of stopping excessive alcohol use $(\mathrm{OR}=2.57[1.40,4.70])$ and decreases the odds of starting excessive alcohol use $(\mathrm{OR}=0.32$ $[0.17,0.62])$. However, it increases the odds of becoming physically inactive $(\mathrm{OR}=1.77[1.05,2.96])$.

Education: As shown in Table 2, the likelihood of being a daily smoker in 2004 decreases as the level of education increases $(\mathrm{OR}=0.82[0.71,0.95])$. In addition, among those who are engaged in extensive or moderate physical activity in 2004 , higher-educated individuals have lower odds $(\mathrm{OR}=0.66$ $[0.49,0.89])$ to negatively change their behavior and become physically inactive in 2007 compared to lower-educated individuals (Table 4).

Annual gross household income quintile: As mentioned earlier, we include the interaction term between income and the type of insurance in our models which appears statistically significant for excessive alcohol use and stopping excessive alcohol use. Thus, the effect of income among those with private insurance is determined by the two corresponding odds ratios (ie, income quintile and interaction term between income quintile and having private insurance). Our results show that a one unit increase in household income quintile increases the odds of excessive alcohol use $(\mathrm{OR}=1.34)$ in 2004. At the same time, one unit increase in household income quintile increases the odds of stopping excessive alcohol use $(\mathrm{OR}=1.69)^{[1]}$. Among those with compulsory social health insurance, the effect of income quintile is not statistically significant for both health-related behaviors and change in behaviors.

The results of the multinominal approach can be found in Appendix 2, with the base category of those who continue healthy behavior, show that those who are in an older age group, live with a partner, and have more education in 2004 are less likely to continue daily smoking in 2007 . Women are also less likely to continue excessive alcohol use.

Health Status Variables

Our findings demonstrate that a one unit increase in selfperceived health decreases the odds of daily smoking 
Table 4. Negative Change in Health-Related Behavior in 2007 (Logit Estimates)

\begin{tabular}{|c|c|c|c|c|c|c|}
\hline & \multicolumn{2}{|c|}{ Start Daily Smoking } & \multicolumn{2}{|c|}{ Start Excessive Alcohol Use } & \multicolumn{2}{|c|}{ Start Physical Inactivity } \\
\hline & OR & $95 \% \mathrm{Cl}$ & OR & $95 \% \mathrm{Cl}$ & OR & $95 \% \mathrm{Cl}$ \\
\hline \multicolumn{7}{|l|}{ Explanatory variables } \\
\hline Age $\leq 55$ & 1.00 & - & 1.00 & - & 1.00 & - \\
\hline Age $56-64$ & 1.81 & {$[0.73,4.53]$} & 1.60 & {$[0.77,3.33]$} & 1.21 & {$[0.58,2.54]$} \\
\hline Age $65-74$ & 0.43 & {$[0.12,1.47]$} & 0.99 & {$[0.41,2.37]$} & 1.66 & {$[0.77,3.56]$} \\
\hline Age $\geq 75$ & 0.55 & {$[0.14,2.17]$} & $0.24^{a}$ & {$[0.05,1.14]$} & $3.02^{\mathrm{c}}$ & {$[1.31,6.95]$} \\
\hline Male & 1.00 & - & 1.00 & - & 1.00 & - \\
\hline Female & 1.24 & {$[0.59,2.62]$} & $0.32^{\mathrm{c}}$ & {$[0.17,0.62]$} & $1.77^{\mathrm{b}}$ & {$[1.05,2.96]$} \\
\hline Living without partner & 1.00 & - & 1.00 & - & 1.00 & - \\
\hline Living with partner & 0.67 & {$[0.27,1.68]$} & $0.53^{\mathrm{a}}$ & {$[0.26,1.10]$} & 1.34 & {$[0.71,2.52]$} \\
\hline No change in marital status & 1.00 & - & 1.00 & - & 1.00 & - \\
\hline Change in marital status & 1.95 & {$[0.40,9.51]$} & 0.68 & {$[0.08,5.48]$} & 1.87 & {$[0.68,5.15]$} \\
\hline Education $^{d}$ & 1.04 & {$[0.68,1.59]$} & $1.35^{\mathrm{a}}$ & {$[0.95,1.93]$} & $0.66^{c}$ & {$[0.49,0.89]$} \\
\hline Annual HH gross income quintile ${ }^{d}$ & 0.75 & {$[0.52,1.08]$} & 0.92 & {$[0.67,1.25]$} & 0.99 & {$[0.77,1.27]$} \\
\hline Perceived health $^{d}$ & $0.57^{b}$ & {$[0.36,0.90]$} & 0.97 & {$[0.68,1.38]$} & $0.53^{c}$ & {$[0.38,0.73]$} \\
\hline GALI, not-limited & 1.00 & - & 1.00 & - & 1.00 & - \\
\hline GALI, limited & $0.21^{\mathrm{b}}$ & {$[0.05,0.82]$} & 0.78 & {$[0.32,1.94]$} & 1.91 & {$[0.87,4.19]$} \\
\hline Health insurance deductible ${ }^{d}$ & 1.09 & {$[0.77,1.55]$} & 1.01 & {$[0.77,1.34]$} & 0.93 & {$[0.70,1.24]$} \\
\hline Social insurance & 1.00 & - & 1.00 & - & 1.00 & - \\
\hline Private insurance & 0.29 & {$[0.03,2.58]$} & 0.52 & {$[0.09,3.08]$} & 1.44 & {$[0.38,5.46]$} \\
\hline \multicolumn{7}{|l|}{ Change in 2007} \\
\hline Same or worse perceived health & 1.00 & - & 1.00 & - & 1.00 & - \\
\hline Better perceived health & 1.42 & {$[0.44,4.57]$} & 0.90 & {$[0.26,3.15]$} & 0.48 & {$[0.11,2.10]$} \\
\hline Same or better perceived health & 1.00 & - & 1.00 & - & 1.00 & - \\
\hline Worse perceived health & 1.63 & {$[0.68,3.92]$} & 1.58 & {$[0.76,3.29]$} & $2.00^{\circ}$ & {$[1.19,3.34]$} \\
\hline No change in limited GALI & 1.00 & - & 1.00 & - & 1.00 & - \\
\hline Non-limited GALI & $6.96^{c}$ & {$[1.85,26.19]$} & 1.49 & {$[0.54,4.14]$} & 0.66 & {$[0.29,1.46]$} \\
\hline No change in non-limited GALI & 1.00 & - & 1.00 & - & 1.00 & - \\
\hline Limited GALI & $2.31^{\mathrm{a}}$ & {$[0.92,5.85]$} & 1.27 & {$[0.55,2.94]$} & $3.18^{\mathrm{c}}$ & {$[1.48,6.83]$} \\
\hline Same or worse health insurance coverage & 1.00 & - & 1.00 & - & 1.00 & - \\
\hline Better health insurance coverage & $0.14^{\mathrm{a}}$ & {$[0.02,1.12]$} & 1.17 & {$[0.50,2.77]$} & 0.89 & {$[0.39,2.00]$} \\
\hline Same or better health insurance coverage & 1.00 & - & 1.00 & - & 1.00 & - \\
\hline Worse health insurance coverage & 0.25 & {$[0.03,1.94]$} & 1.49 & {$[0.55,3.99]$} & $0.32^{\mathrm{a}}$ & {$[0.09,1.10]$} \\
\hline \multicolumn{7}{|l|}{ Interaction } \\
\hline $\mathrm{HH}$ income quintile* private insurance & 1.41 & {$[0.77,2.59]$} & 1.25 & {$[0.78,2.02]$} & 1.10 & {$[0.75,1.63]$} \\
\hline \multirow[t]{2}{*}{ Other model specification } & \multicolumn{2}{|c|}{ Pseudo R2 .128 } & \multicolumn{2}{|c|}{ Pseudo R2.079 } & \multicolumn{2}{|c|}{ Pseudo R2.163 } \\
\hline & \multicolumn{2}{|c|}{ Model $\chi^{2}(19)^{c} 39.58$} & \multicolumn{2}{|c|}{ Model $\chi^{2}(19)^{b} 39.92$} & \multicolumn{2}{|c|}{ Model $\chi^{2}(18)^{c} 102.52$} \\
\hline $\mathrm{N}$ (included in analysis) & \multicolumn{2}{|c|}{1162} & \multicolumn{2}{|c|}{1257} & \multicolumn{2}{|c|}{1470} \\
\hline
\end{tabular}

Abbreviation: GALI, Global Activity Limitation Index.

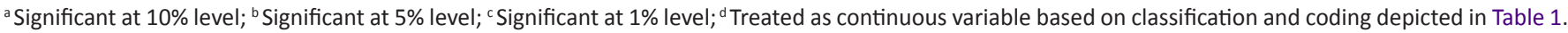
The age groups are compared to age $\leq 55$.

$(\mathrm{OR}=0.79[0.69,0.91])$ and physical inactivity $(\mathrm{OR}=0.32$ $[0.22,0.47])$ in 2004 (Table 2) and the odds of their negative change (ie, start daily smoking and start physical inactivity) in $2007(\mathrm{OR}=0.57[0.36,0.90]$ and $0.53[0.38,0.73]$, respectively) (Table 4). It also increases the odds of a positive change in smoking $(\mathrm{OR}=1.44[1.02,2.04])$ (Table 3$)$. Those who perceive a deterioration in their health condition between 2004 and 2007 are considerably more likely $(\mathrm{OR}=3.96[1.90,8.23])$ to quit daily smoking (Table 3 ), but also to become physically inactive $(\mathrm{OR}=2.00[1.19,3.34])$ (Table 4$)$ than those who do not perceive any change in health status.

The results of the multinominal model show that those who have a higher self-perceived health in 2004 are less likely to continue daily smoking as well as physical inactivity in 2007. At the same time, those with limited GALI in 2007 are less likely to continue daily smoking in 2007 (see Appendix 2).

Health Insurance Variables

As mentioned earlier, the interaction term between the type of health insurance and income quintile is statistically significant for excessive alcohol use and stopping excessive alcohol use. As a result, the effect of the type of health insurance is determined by the two corresponding odds ratios (ie, having private insurance and interaction term between income quintile and having private insurance). Thus, among the individuals at the lowest income quintile (income quintile $=1$ ), those with voluntary private insurance rather than those with compulsory social insurance have lower odds of excessive alcohol use $(\mathrm{OR}=0.62)$ in 2004 as well as lower odds of stopping excessive alcohol use between 2004 and 2007 $(\mathrm{OR}=0.13)^{[2]}$. However, among individuals in the highest income quintile, those with private insurance rather than those with compulsory social insurance have higher odds of excessive alcohol use $(\mathrm{OR}=1.68)$ in 2004, as well as higher odds of stopping excessive alcohol use $(\mathrm{OR}=1.10)$ in 2007. To double check our results, we also calculated the marginal effect of the income quintile as well as the incremental effect of having private insurance on the conditional probability of the 
respective behavior when taking into account the interaction term (all appeared consistent with odds ratio we present). With regard to the effect of change in health insurance coverage on a change in health-related behavior, our results (Table 3) show that those with a worse health insurance coverage in 2007 compared to 2004 are less likely $(\mathrm{OR}=0.19$ $[0.06,0.57])$ to stop excessive alcohol use in 2007. The effect of changes in health insurance coverage on positive or negative change in two other health-related behaviors analyzed in this study did not appear to be statistically significant.

Considering the results of our multinominal approach (see Appendix 2), we find that those with a better perceived insurance coverage in 2007 are less likely to continue daily smoking and excessive alcohol use in that year. Those with worse perceived health insurance coverage in 2007 are more likely to pursue excessive alcohol use at the same year. We also find that those with private insurance in 2004 have higher odds of continuing daily smoking in 2007. The size of this effect also depends on the level of the annual household gross income quintile. That is belonging to a higher income quintile in 2004 increases the chance of continuing daily smoking in 2007.

\section{Discussion}

Our study is one of few ${ }^{33,34}$ which analyzes the joint effect of socio-economic, health status, and health insurance coverage on three health-related behaviors (ie, daily smoking, excessive alcohol use, and physical inactivity) as well as the changes in these behaviors. Much research so far has solely focused on socio-economic factors and health status. ${ }^{4-8}$ Most studies have examined the effect of some of these factors on only one type of unhealthy behavior. ${ }^{9,22-25}$ Few studies have actually considered health insurance as a potential factor which due to ex-ante moral hazard can also have an effect on individuals' health-related behavior. In addition to using a comprehensive set of factors (ie, socio-economic, health status, and health insurance coverage), we exploit the same set of factors for all behaviors. This gives us the possibility to show whether and to what extent the effects of explanatory variables are consistent among different behaviors. Moreover, the panel nature of our dataset enables us to analyze how changes in health-related behavior can be related to changes in health status or health insurance coverage. However, it should be emphasized again that given the age specification of the SHARE dataset, our results refer to people aged 50 and over. It should be also noted that in order to name those above mentioned behaviors health-related behaviors, we have referred to previous literature ${ }^{1}$ which considers those behaviors as unhealthy behaviors due to their important role in acquiring chronic diseases regardless of their potential direct effect on individuals' health status.

\section{Indicators of Health-Related Behaviors}

We find that the most consistent predictor of health-related behavior among all three behaviors is gender although it affects each behavior differently. Previous studies also find that the most common types of health-related behaviors are gender-specific, which is of interest for health promotion activities. ${ }^{9,10,16}$ Although, our results regarding the socioeconomic determinants of daily smoking are compatible with previous studies, ${ }^{4,9-15}$ we did not capture all associations found in previous studies for alcohol consumption. ${ }^{10,17}$ This may to a certain extent be because of the variation in the way drinking behavior is measured and reported in different studies. ${ }^{11}$ It can also be explained by the fact that we use a wider range of factors which might pick up the effect of other socioeconomic variables.

Our findings show that each health behavior has its own set of determinants. As a result, health-related behavior cannot be treated as one concept and each behavior should be considered separately. For instance, we find that men are vulnerable to smoking and excessive alcohol use, while those who are older are vulnerable to physical inactivity. These findings can provide a framework in targeting policies for health programs aimed at individuals' behavioral change towards a healthier lifestyle.

\section{Indicators of Change in Health-Related Behavior}

In our study a number of baseline factors and change events predict behavior change, but these are not consistent across all three health-related behaviors. This applies regardless of how we model the change (either using a logit or a multinominal approach). For instance, women are more likely to stop heavy drinking while, at the same time, they are also more likely to become physically inactive. In addition, living with a partner which could encourage positive change in smoking behavior and physical activity, has no such effect on changing drinking behavior. These results are also consistent with previous studies. ${ }^{11,12,35,36}$

Health-related variables seem to be the most consistent predictors of changes among all health-related behaviors. An optimal self-perceived health in baseline year (2004) encourages positive and discourages negative change in health-related behavior. While our findings imply that people with poorer self-perceived health are those who tend to undertake more unhealthy behaviors (daily smoking and physical inactivity in current analysis), there is also evidence showing the role of unhealthy behavior as a cause of poor selfperceived health. ${ }^{6,18}$ This indicates a limitation of our study since we are not able to establish whether poor self-perceived health is caused by smoking or vice versa.

Nevertheless, we find that a deteriorated self-perceived health in the follow-up year (2007) compared to the baseline year (2004) leads individuals to quit smoking, but to start physical inactivity. For smoking, it may be due to the fact that our sample includes predominantly elderly persons and at this age, the long-term health consequences of smoking are experienced by the elderly themselves or by others of their own age, which may make them more conscious about the need to change. For physical inactivity, it may be due to individuals' lower ability for physical activity over time. This is also consistent with our results for GALI as we find that those, whose GALI changed from not-limited to limited, are more likely to become physically inactive. As mentioned earlier, the GALI measures the limitation on activity which is because of a health problem. Thus, becoming physically inactive might be a part of the normal process of aging and then could not be totally considered as a negative change in health-related behavior. Nevertheless, physical inactivity as defined by the SHARE means not even engaging in activities that require 
a moderate level of energy such as gardening, doing a walk, etc. It might imply a sedentary lifestyle which should raise concern given the fact that the large body of evidence points toward its role in increasing all-cause mortality. ${ }^{37}$ On this account, even though the aging process might increase the interval of physical activity or shift it to a mildly energetic activity, it should not completely stop it. It should be noted that this interpretation is based on individual behavior. It is well-documented that social ties and supports may have a very important role to sustain or improve health behavior. ${ }^{38}$ Some studies have shown that family support for physical activity, and household inventory for physical activity equipment have a direct effect on physical activity. ${ }^{39}$ It is also worth noting that when we left those with limitation on activity out from the model of negative change in physical activity (2007), the effect of age and gender on starting physical inactivity disappeared. Thus, the effect of age and gender on becoming physically inactive in 2007 (as reported in Table 3) seems to be mostly driven by those who have limitation on activity.

This shows that the dynamics of each behavior (positive or negative change) is not necessarily determined by the same factors determining the state of that behavior. In other words, factors that affect a given health-related behavior might have no association with the change in this behavior. However, our results show that when a factor has an effect, its effect is consistent among the state and dynamics of that behavior. For instance, we find that women are more likely to stop excessive alcohol use and less likely to start excessive alcohol use. Similarly, we find that those who live with a partner have more chance to quit daily smoking. Both findings are consistent with our results from the baseline year indicating that women are less likely to be excessive alcohol users and that daily smoking is less prevalent among those who live with a partner. This consistency can clearly be used to identify population groups that are most likely to have an unhealthy lifestyle.

It might be argued that the change in health-related behavior might be due to some policy change. For instance, the ban on smoking would affect smoking behavior. In the Netherlands smoking has been banned in government building and public places (since 1990) and in workplace (since 2004) with the exception of the hospitality industry. However, as smoking ban in public places dates back to many years prior to 2004, it cannot be considered as a new policy change. However, given the data at hand, we are not able to grasp the effect of smoking ban in workplace on our study population. It is worth noting that starting daily smoking at older age is most probably a relapse, because previous studies has already shown that starting smoking for the first time even after the age of 25 is very unlikely. ${ }^{25}$

Income and Health Insurance-Related Indicators

We discuss here the effect of health insurance together with the effect of income, as in our study, their effects on healthrelated behaviors are dependent to each other due to the specificities of the Dutch healthcare system. We find an effect of income only among those who had private insurance in 2004. That is, being in a higher income quintile increases the odds of excessive alcohol use. Previous studies have shown that alcohol consumption is associated with higher income, ${ }^{17,40}$ while, in contrast, smoking is associated with lower income. ${ }^{4,9,10,15}$ However, our results should be interpreted given the specificity of private insurance in the Netherlands. As mentioned in the Background section, individuals whose annual individual gross income was higher than a certain level set by the government were not eligible for compulsory social insurance. They could voluntarily buy private insurance. However, income was not the only factor that determines the type of health insurance. Besides those who bought voluntary health insurance, private health insurance also included two other categories of individuals whose income were the same or even lower than those insured by compulsory social insurance. Public servants and elderly people with low-income had private insurance, but were in many respects more similar to people with social insurance. In other words, people with private insurance comprised a quite heterogeneous group in terms of income. This might explain why the effect of income is observed only among this group and not among those with compulsory social insurance which seems to be a more homogenous group in terms of income.

At the same time, the combined effect of income and type of insurance deters us to draw a general conclusion about the effect of type of insurance. Moreover, the type of health insurance in the Netherlands in 2004 mainly referred to differences in financing and not necessarily to a difference in health insurance coverage.

Nevertheless, for some health-related behavior analyzed in this study, we find that worse perceived health insurance coverage in 2007 is associated with a lower likelihood of a positive change (eg, stopping excessive alcohol use) in that year. Our results also show that those individuals, who reported that they had a better insurance coverage in 2007 than 2004, tend not to continue their unhealthy lifestyle in 2007 while those who reported that their health insurance coverage had deteriorated tend to continue their unhealthy lifestyle. These results are not supportive for the existence of ex-ante moral hazard, and even imply the contrary. Because, should ex-ante moral hazard exists, we expect that a positive change in health insurance coverage (having perceived a better coverage in 2007) leads to negative change in health behavior (eg, start smoking, excessive alcohol use or physical inactivity). However, as mentioned above, our results show the opposite. Previous studies on the effect of health insurance on health behavior have come to contradictory conclusions. Some studies show that individuals without health insurance are more likely to undertake healthy behavior than those who have social health insurance. ${ }^{34}$ In contrast, other studies find a higher tendency for healthy behavior among privately insured people who enjoy a more generous insurance coverage. ${ }^{33}$ Despite this contradiction in the findings of different studies, it is often noted that ex-ante moral hazard is unlikely to be a significant problem in the context of health insurance. It is because of the nature of health which is an irreplaceable commodity. Thus, a health loss is never fully insured, which means that there are always incentives for the prevention of illness.

A recent study by Dave and Keastner ${ }^{19}$ put forth an explanation why ex-ante moral hazard might not be seen as a significant problem in health insurance. They describe a direct and an indirect effect of health insurance on health behavior. They 
explain that health insurance on the one hand, increases the contact with physician and thus the patient will have easier access to their advice and consultation. On the other hand, health insurance may have a direct moral hazard effect on health behavior which reduces the incentive for prevention. Thus, the existence of these two offsetting effects makes a detection of a pure ex-ante moral hazard even harder. Dave and Keastner ${ }^{19}$ show that if contacts with a medical professional are controlled for, obtaining health insurance reduces prevention and increases unhealthy behavior in the United States. Consequently, they advise policy-makers to remove copayments and annual deductible applied to visits the physician in order to encourage more contacts with medical professional.

However, the explanation provided by Dave and Keastner ${ }^{19}$ seems hardly applicable to other settings than the United States. For instance, in some European countries, no fee is applicable for visits to general practitioner (GP). ${ }^{41}$ In addition, the healthcare system is designed to provide access to primary care where a GP plays an important role not only as a first contact for the patient, but also as a gate keeper for the healthcare system. For instance, in the Netherlands the basic package always includes visits to the GP and also the mandatory deductible does not hold for a visit to the GP. Nevertheless, the existing evidence about ex-ante moral hazard in Europe is limited and mixed, thus not convincing. Yet, it is important to notice that individually perceived change in health insurance coverage should not be interpreted as the effect of the reform. As mentioned earlier, given the data at hand, our analysis is not designed to study the effect of health insurance reform in the Netherlands. Instead, it is limited to explore factors, including health insurance, associated with an individual's choice of unhealthy behavior and the decision to change this behavior which accordingly limits a causal interpretation of the results. There are also other limitations to be acknowledged. Although an unhealthy diet is considered a rather common health-related behavior, we could not include it in our study because it has not been included in the SHARE section on health-related behaviors. The other limitation is the one that self-reported data, in general, would pose on the analysis. Also, we could not study the effect of having no insurance on changes in behavior since the change models ran very low on the number of observation for this group.

\section{Conclusion and Policy Implications}

Having exploited the same set of factors for three healthrelated behaviors and their positive or negative change, we are able to make a comparison across different health behaviors among people at age 50 or older. These findings show that a variety of factors (ie, socio-demographic, socio-economic, health status, and health insurance coverage) are associated with health-related behaviors but not in a consistent way across all behaviors. Moreover, the dynamics of a health-related behavior and the state of that behavior are not necessarily associated with the same factors. Therefore, health-related behavior could not be treated as one concept and each behavior should rather be considered separately. Thus, our results provide inputs to target policies towards individuals in need of lifestyle change. More effort is needed to target men and affluent people to quit smoking and excessive alcohol use, as well as women and the elderly to become physically more active. The combined effect of income and type of insurance, which is one specification of Dutch health insurance system in 2004 , deters us to see the effect of type of insurance. However, we find that better perceived health insurance coverage is associated with a healthier lifestyle which is not compatible with an ex-ante moral hazard interpretation. It suggests that what we have found is not compatible with ex-ante moral hazard interpretation. Thus, policy-makers should not be so worried that insurance coverage for preventive services and facilities which make preventive activities more feasible, would lead to less prevention. Therefore, subsidizing primary prevention and providing financial incentive to engaging individual in healthier lifestyle can be recommended. Future research should be designed to identify a causal effect of health insurance on health behavior in different countries, accounting, at the same time, for the context of each country to separate the effect of institutions from the pure effect of insurance.

\section{Acknowledgments}

The authors thank anonymous referees for their thoughtful comments. This publication is related to the project ProHealth 65+ (GA 20131210) which has received funding from the European Union, in the framework of the Health Program (2008-2013). The content of this publication represents the views of the authors and it is their sole responsibility; it can in no way be taken to reflect the views of the European Commission or any other body of the European Union. The European Commission does not accept responsibility for any use that may be made of the information it contains. This paper uses data from SHARE release 2.5.0, as of May 24, 2011. The SHARE data collection has been primarily funded by the European Commission through the fifth framework program (project QLK6-CT-2001-00360 in the thematic program Quality of Life), through the sixth framework program (projects SHARE-I3, RII-CT-2006-062193, COMPARE, CIT5-CT-2005-028857, and SHARELIFE, CIT4-CT-2006-028812) and through the seventh framework program (SHARE-PREP, 211909 and SHARE-LEAP, 227822). Additional funding from the U.S. National Institute on Aging (U01 AG09740-13S2, P01 AG005842, P01 AG08291, P30 AG12815, Y1-AG-4553-01 and OGHA 04-064, IAG BSR0611, R21 AG025169) as well as from various national sources is gratefully acknowledged (see http://www.share-project.org for a full list of funding institutions).

\section{Authors' contributions}

RR developed the design, carried out the data analysis, and drafted the manuscript. MP assisted in the design of the study and revision of the manuscript. WG assisted in the design of the study and revision of the manuscript. All authors read and approved the final manuscript.

\section{Ethical issues}

This empirical study is based on data from the Survey of Health, Aging, and Retirement in Europe (SHARE). SHARE data is freely and openly accessible for scientific purpose. The SHARE Research Data Center complies with the Criteria of the German Council for Social and Economic Data for providing access to micro data. Hence, ethical approval was not obtained for this research.

The authors declare that they have no competing interests. 


\section{Endnotes}

[1] Let $\beta_{1}, \beta_{2}$, and $\beta_{12}$ denote the coefficients related to annual gross household income quintile, private insurance, and the interaction term, respectively. Then, the odds ratio of respective dependent variable for one unit change in income quintile is calculated by $\mathrm{e}^{\beta 1 *} \mathrm{e}^{\beta 12}$ among those with private health insurance. Having substituted odds ratio from Tables 2-4 we get the odds ratio for respective behavior as presented in the text, that are: $1.34\left(1.05^{* 1.28)}\right.$ and $1.69(1 * 1.69)$ for excessive alcohol use, and stopping excessive alcohol use, respectively. However, the corresponding odds ratio for those with compulsory social insurance is $\mathrm{e}^{\beta 1}$ which is the odds ratio of respective behavior for annual gross household income quintile as presented in Tables 2-4.

[2] Using the same denotation as previous footnote, the difference between the odds ratio of respective behavior for those with private insurance and those

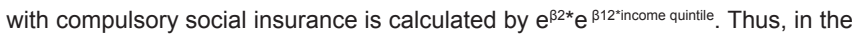
lowest income quintile (income quintile $=1$ ), having substituted respective odds ratio from the Tables 2-4 we will get the odds ratio presented in the text, that are: $0.62\left(0.49^{\star} 1.28^{\wedge} 1\right)$ for excessive alcohols as well as $0.13\left(0.08^{\star} 1.69^{\wedge} 1\right)$ for stopping excessive alcohol use. To get the respective odds ratio in the highest income quintile (income quintile $=5$ ) as presented in the text, the number 1 should be replace by 5

\section{Authors' affiliations}

${ }^{1}$ Health Management and Economics Research Center (HMERC), Isfahan University of Medial Sciences, Isfahan, Iran. ${ }^{2}$ Department of Health Services Research, CAPHRI, FHML, Maastricht University, Maastricht, The Netherlands. ${ }^{3}$ Top Institute for Evidence-Based Education Research (TIER), Maastricht University, Maastricht, The Netherlands.

\section{References}

1. Alwan A. Global status report on noncommunicable diseases 2010. Geneva: World Health Organization; 2011.

2. Mackenbach J. Health and health care. In: Borsch-Supan A, Brugiavini A, jurges H, Mackenbach J, Siegrist J, Weber G, eds. Health, ageing and retirement in Europe: First results from the survey of health, ageing and retirement in Europe. Mannheim, Germany: Mannheim Research Institute for the Economics of Aging (MEA); 2005:81-162.

3. UN. Res/66/2. Political declaration of the high-level meeting of the general assembly on the prevention and control of noncommunicable diseases (resolutions adopted by the general assembly at its 66th session); 2011.

4. Harper S, Lynch J. Trends in socioeconomic inequalities in adult health behaviors among us states, 1990-2004. Public Health Rep. 2007;122:177-189.

5. Newsom JT, Huguet N, McCarthy MJ, et al. Health behavior change following chronic illness in middle and later life. J Gerontol B Psychol Sci Soc Sci. 2012;67B(3):279-288. doi:10.1093/geronb/ gbr103

6. Johnson PB, Richter $\mathrm{L}$. The relationship between smoking, drinking, and adolescents' self-perceived health and frequency of hospitalization: analyses from the 1997 national household survey on drug abuse. J Adolesc Health. 2002;30(3):175-183. doi:10.1016/s1054-139x(01)00317-2

7. Shankar A, McMunn A, Steptoe A. Health-related behaviors in older adults: Relationships with socioeconomic status. Am J Prev Med. 2010;38:39-46. doi:10.1016/j.amepre.2009.08.026

8. Laaksonen M, Prättälä R, Lahelma E. Sociodemographic determinants of multiple unhealthy behaviours. Scand J Public Health. 2003;31:37-43. doi:10.1080/14034940210133915

9. Nagelhout GE, de Korte-de Boer D, Kunst AE, et al. Trends in socioeconomic inequalities in smoking prevalence, consumption, initiation, and cessation between 2001 and 2008 in the Netherlands. Findings from a national population survey. BMC Public Health. 2012;12:303. doi:10.1186/1471-2458-12-303

10. Hughes MC, Hannon PA, Harris JR, Patrick DL. Health behaviors of employed and insured adults in the united states, 20042005. Am J Health Promot. 2010;24(5):315-323. doi:10.4278/ ajhp.080603-quan-77

11. Molander RC, Yonker JA, Krahn DD. Age-related changes in drinking patterns from mid to older age: Results from the Wisconsin longitudinal study. Alcoholism: Clinical and Experimental Research. 2010;34(7):1182-1192. doi:10.1111/j.1530-0277.2010.01195.x

12. Nystedt P. Marital life course events and smoking behaviour in Sweden 1980-2000. Soc Sci Med. 2006;62(6):1427-1442. doi:10.1016/j.socscimed.2005.08.009

13. Cho HJ, Khang $\mathrm{YH}$, Jun HJ, Kawachi I. Marital status and smoking in Korea: The influence of gender and age. Soc Sci Med. 2008;66(3):609-619. doi:10.1016/j.socscimed.2007.10.005

14. Kiecolt-Glaser JK, Newton TL. Marriage and health: His and hers. Psychol Bull. 2001;127:472-503. doi:10.1037//00332909.127.4.472

15. Smith P, Frank J, Mustard C. Trends in educational inequalities in smoking and physical activity in Canada: 1974-2005. J Epidemiol Community Health. 2009;63:317-323. doi:10.1136/ jech.2008.078204

16. Stock C, Wille L, Krämer A. Gender-specific health behaviors of German university students predict the interest in campus health promotion. Health Promot Int. 2001;16(2):145-154. doi:10.1093/ heapro/16.2.145

17. Moore AA, Gould R, Reuben DB, et al. Longitudinal patterns and predictors of alcohol consumption in the united states. Am J Public Health. 2005;95(3):458-464. doi:10.2105/ajph.2003.019471

18. Manderbacka K, Lundberg $\mathrm{O}$, Martikainen $\mathrm{P}$. Do risk factors and health behaviours contribute to self-ratings of health? Soc Sci Med. 1999;48(12):1713-1720. doi:10.1016/s0277-9536(99)00068-4

19. Dave D, Kaestner R. Health insurance and ex ante moral hazard: Evidence from medicare. Int $J$ Health Care Finance Econ. 2009;9(4):367-390. doi:10.1007/s10754-009-9056-4

20. Kenkel DS. Prevention. In: Culyer A, Newhouse JP, eds. Handbook of Health Economics. Elsevier: North-Holland; 2000:1676-1720.

21. Rezayatmand R, Pavlova M, Groot W. The impact of out-of-pocket payments on prevention and health-related lifestyle: A systematic literature review. Eur J Public Health. 2013;23:74-79. doi:10.1093/ eurpub/cks034

22. Clemens SL, Matthews SL, Young AF, Powers JR. Alcohol consumption of Australian women: Results from the Australian longitudinal study on women's health. Drug Alcohol Rev. 2007;26(5):525-535. doi:10.1080/09595230701499142

23. Merrick EL, Horgan CM, Hodgkin D, Garnick DW, Houghton SF, Panas L, Saitz R, Blow FC. Unhealthy drinking patterns in older adults: Prevalence and associated characteristics. J Am Geriatr Soc. 2008;56(2):214-223. doi:10.1111/j.1532-5415.2007.01539.x

24. Platt A, Sloan FA, Costanzo P. Alcohol-consumption trajectories and associated characteristics among adults older than age 50. J Stud Alcohol Drugs. 2010;71(2):169-179. doi:10.15288/ jsad.2010.71.169

25. Willemsen MC, Hoogenveen RT, Van Der Lucht F. New smokers and quitters. Eur J Public Health. 2002;12:136-138. doi:10.1093/ eurpub/12.2.136

26. Bergrath E, Pavlova M, Groot W. Attracting health insurance buyers through selective contracting: Results of a discrete-choice experiment among users of hospital services in the Netherlands. Risks. 2014;2(2):146-170. doi:10.3390/risks2020146

27. Leu RE, Fund C. The swiss and dutch health insurance systems: Universal coverage and regulated competitive insurance markets. New York, NY: Commonwealth Fund; 2009.

28. Survey of health, aging and retirement in Europe (SHARE) website. http://www.share-project.org/. Accessed November 13, 2012.

29. De Luca G, Peracchi F. Survey response. In: Borsch-Supan A Brugiavini A, Jurges $\mathrm{H}$, Siegrist J, Weber G, eds. First Results From the Survey of Health, Aging, and Retirement in Europe. Mannheim, Germany: Mannheim Research Institute for the Economics of Aging (MEA); 2005.

30. Schroder M. Attriton. In: Borsch-Supan A, Brugiavini A, Jurges $H$, Kapteyn A, Mackenbach J, Siegrist J, Weber G. eds. First Results From the Survey of Health, Ageing and Retirement in Europe 
(2004-2007): Starting the Longitudinal Dimension. Mannheim, Germany: Mannheim Research Institute for the Economics of Aging (MEA); 2008.

31. Klevmarken A, Hesselius $P$, Swensson $B$. The share sampling procedures and calibrated designs weights. In: Borsch-Supan A, Jurges $\mathrm{H}$, eds. The Survey of Health, Aging, and Retirement in Europe-Methodology. Mannheim, Germany: Mannheim Research Institute for the Economics of Aging (MEA); 2005:28-69.

32. Jagger C, Gillies C, Cambois E, Van Oyen H, Nusselder W, Robine J-M. The global activity limitation index measured function and disability similarly across European countries. J Clin Epidemiol. 2010;63:892-899. doi:10.1016/j.jclinepi.2009.11.002

33. Courbage $C$, Coulon AD. Prevention and private health insurance in the UK. The Geneva Papers on Risk and Insurance Theory. 2004;29:719-727. doi:10.1111/j.1468-0440.2004.00313.x

34. Schneider U, Zerth J. Improving prevention compliance through appropriate incentives: Theoretical modelling and empirical evidence. Swiss Journal of Economics and Statistics. 2011;147:71106.

35. Van Loon AJM, Tijhuis M, Surtees PG, Ormel J. Determinants of smoking status: Cross-sectional data on smoking initiation and cessation. Eur J Public Health. 2005;15:256-261. doi:10.1093/ eurpub/cki077
36. Eng PM, Kawachi I, Fitzmaurice G, Rimm EB. Effects of marital transitions on changes in dietary and other health behaviours in us male health professionals. J Epidemiol Community Health. 2005;59(1):56-62. doi:10.1136/jech.2004.020073

37. Kahn EB, Ramsey LT, Brownson RC, et al. The effectiveness of interventions to increase physical activity: a systematic review. Am J Prev Med. 2002;22(4):73-107. doi:10.1016/s07493797(02)00434-8

38. Thoits PA. Mechanisms linking social ties and support to physical and mental health. J Health Soc Behav. 2011;52(2):145-161. doi:10.1177/0022146510395592

39. Kegler M, Swan D, Alcantara I, Feldman L, Glanz K. The influence of rural home and neighborhood environments on healthy eating, physical activity, and weight. Prev Sci. 2014;15(1):1-11. doi:10.1007/s11121-012-0349-3

40. Costa-i-Font J, Hernández-Quevedo C, Jiménez-Rubio D. Do income gradients in unhealthy behaviours explain patterns of health inequalities? London: LSE Health; 2012.

41. Tambor M, Pavlova M, Woch P, Groot W. Diversity and dynamics of patient cost-sharing for physicians' and hospital services in the 27 European union countries. Eur J Public Health. 2011;21:585590. doi:10.1093/eurpub/ckq139

Appendix 1

\begin{tabular}{|c|c|c|}
\hline $\begin{array}{l}\text { Variables and Coding Used in } \\
\text { the Analysis }\end{array}$ & $\begin{array}{l}\text { Original Variables in } \\
\text { the SHARE Dataset }\end{array}$ & Variable Description \\
\hline \multicolumn{3}{|l|}{ Dependent variable } \\
\hline $\begin{array}{l}\text { Current daily smoking } \\
0=\text { No } \\
1=\text { Yes }\end{array}$ & BR001\&BR002 & $\begin{array}{l}\text { This variable indicates whether the participant is daily smoker. Participants were first asked } \\
\text { if they had ever smoked cigarettes, cigars, cigarillos or a pipe daily for a period of at least } \\
\text { one year. If they replied in the affirmative, they were asked whether or not they smoked at } \\
\text { present time. Respondents who answered "Yes" to both questions are classified as current } \\
\text { daily smoker. }\end{array}$ \\
\hline $\begin{array}{l}\text { Excessive alcohol use } \\
0=\text { No } \\
1=\text { Yes }\end{array}$ & DRINKIN2 & $\begin{array}{l}\text { This variable indicates the cases of heavy drinking defined by SHARE as drinking more than } \\
\text { two glasses of any of the three main drinks (ie, beer, wine, hard liquor) almost every day or } \\
\text { five/six days a week. The variable is constructed by SHARE based on variables BRO11, BR012, } \\
\text { and BR013. These variables contain information on the frequency of drinking more than two } \\
\text { glasses of beer, wine and hard liquor, respectively. } \\
\text { To collect data for variable BR011, the following question was asked: "During the last } 6 \text { months, } \\
\text { how often have you had more than two glasses or cans of beer or cider in a single day?" The } \\
\text { following response options were given: } 1 \text {. Almost every day; } 2 \text {. Five or six days a week; } 3 \text {. Three } \\
\text { or four days a week; } 4 \text {. Once or twice a week; } 5 \text {. Once or twice a month; } 6 \text {. Less than once a } \\
\text { month; } 7 \text {. Not at all in the last } 6 \text { months. } \\
\text { The framing of the questions and response categories for variables BR012 and BR013 were } \\
\text { analogous. }\end{array}$ \\
\hline $\begin{array}{l}\text { Physical inactivity } \\
0=\text { No } \\
1=\text { Yes }\end{array}$ & PHACTIV & $\begin{array}{l}\text { This variable indicates the presence of physical inactivity. It is constructed by SHARE based on } \\
\text { variables BRO15 and BRO16. Physical inactivity is defined as never or almost never engaged in } \\
\text { neither moderate nor vigorous physical activity as defined by the following questions: } \\
\text { BR015 SPORTS OR ACTIVITIES THAT ARE VIGOROUS "How often do you engage in vigorous } \\
\text { physical activity, such as sports, heavy housework, or a job that involves physical labor?" } \\
\text { BR016 ACTIVITIES REQUIRING A MODERATE LEVEL OF ENERGY "How often do you engage in } \\
\text { activities that require a low or moderate level of energy such as gardening, cleaning the car, } \\
\text { or doing a walk?" } \\
\text { For both questions, the response categories were defined as follows: } 1 \text {. More than once a } \\
\text { week; } 2 \text {. Once a week; } 3 \text {. One to three times a month; } 4 \text {. Hardly ever, or never. }\end{array}$ \\
\hline
\end{tabular}

\section{Independent variables}

Education

$1=$ ISCED 1

2 = ISCED 2

$3=$ ISCED 3

$4=$ ISCED 5

Annual gross household income quintile

Ranging from

$1=$ Lowest quintile to

$5=$ Highest quintile
This variable shows the level of participant's education according to the 1997 ISCED which is used by SHARE for international comparison. In the Netherlands, the name of the degree mentioned by the participant during the interview was mapped by the local experts to the respective ISCED coding.

This variable provides information on annual gross household income of the participant in 2004. It is generated by SHARE and includes all source of income for each individual in the household (i.e. income from employment and self-employment, all types of pensions, income from rent) and also other sources of income at a household level (i.e. household interest income from bank accounts, bonds, or mutual funds). We use the quintile of this variable in our model as independent variable. 


\begin{tabular}{lll}
\hline $\begin{array}{l}\text { Variables and Coding Used in } \\
\text { the Analysis }\end{array}$ & $\begin{array}{l}\text { Original Variables in } \\
\text { the SHARE Dataset }\end{array} \quad$ Variable Description \\
\hline
\end{tabular}

\section{Self-perceived health}

Ranging from 1 = poor

SPHUS

to $5=$ excellent

This variable is based on variables PH003\&PH0052 in the SHARE dataset, which contains responses to the following question:

"Would you say your health is: 1. Excellent; 2. Very good; 3. Good; 4. Fair; 5. Poor?" For more convenient interpretation we use the reversed order of this variable in our model so that the higher number shows higher perceived health status.

This variable is generated by SHARE and it indicates the global activity limitation index of a participant. It is based on variable PHOO5 in the SHARE dataset, which was obtained using the following question:

Global Activity Limitation Index $0=$ not limited

GALI $1=$ limited "For the past six months at least, to what extent have you been limited because of a health problem in activities people usually do?" The response categories were: 1 . Severely limited; 2. Limited, but not severely; 3 . Not limited.

Thus, variable GALI dichotomizes these three response categories into two categories of limited (sever and not sever) and not limited activities due to health problems.

Social compulsory insurance

$$
0=\text { No }
$$

$1=$ Yes

\section{Private health insurance}

$0=$ No

$1=$ Yes

\section{No insurance}

$0=$ health insurance

$1=$ no health insurance

Better self-perceived health $0=$ worse or the same health

1 = better health

Worse self-perceived health

$0=$ better or the same health

1 = worse health

Non-limited GALI compared to

\section{4}

$0=$ limited or the same

GALI

1 = non-limited
HC059d5, HC059d6 HC059d7

HC057\&HC059dno

PH062

PH062

This variable indicates whether the participants were covered by the National Health Insurance System in 2004 (ie, whether they had compulsory social health insurance). Those who replied in affirmative are classified as individuals with social compulsory health insurance in 2004.

These variables indicate whether the participants with no compulsory social health insurance had any type of private insurance in 2004. Those who replied in positive are considered as having private insurance in 2004.
This variable indicates those who had no health insurance in 2004. Thus, those who had no social health insurance $(\mathrm{HCO57}=0)$ and had no private health insurance $(\mathrm{HCO59dno}=1)$, are classified as having no insurance at all in 2004.
This variable indicates whether the health status of the participant became better in 2007 compared to 2004. In particular, participants in wave 2007 were asked the following: "Compared with your health when we talked with you in (month and year previous interview), would you say that your health is better now, about the same, or worse?" The response options were: 1 . Better; 2 . About the same; 3 . Worse. Thus, those who chose the first option are classified as having better health status in 2007.

This variable indicates whether the health status of the participant became worse in 2007 compared to 2004. It is constructed using the responses to the same question as for variable PH062. Thus, those who chose option 3. Worse, are classified as having worse health status in 2007.

This variable indicates whether the limitation due to health problems was lower in 2007 compared to 2004. It is constructed by comparing the variables GALI (see above) in wave 1 and wave 2 and it shows the change in the global activity limitation index for each respondent between the two waves. Thus, those who had limitations with activity due to health problems in 2004 (GALI in wave $1=1$ ) but had no such limitations in 2007 (GALI for wave $2=0$ ), are classified as non-limited GALI in 2007.

\section{Limited GAL}

$0=$ non-limited or the same

$1=$ Limited

Better health insurance coverage

$0=$ worse or the same coverage

1 = better coverage
This variable indicates whether the limitation due to health problems was higher in 2007 compared to 2004. It is constructed in an analogous way as variable non-limited GALI. Thus, those who had no limitations with activity due to health problems in 2004 (GALI in wave $1=$ 0) but had such limitations in 2007 (GALI for wave 2 =1), are classified as limited GALI in 2007.

This variable indicates whether the insurance coverage of the participant became better in 2007 compared to 2004. In particular, participants in wave 2007 were asked to compare their health insurance coverage with the one they have had during wave 2004 (previous interview). The question was framed as follows: "We are interested in how your health insurance may have changed since our last interview in [\{month year previous interview\}]. Taking all your social and health insurances into account, has anything changed, for better or for worse, in your coverage for health problems since [\{month year previous interview\}]?" The following response options were given: 1 . No change; 2 . Better coverage now; 3 . Worse coverage now. Thus, those who chose the second option are classified as having better coverage in 2007.

This variable indicates whether the insurance coverage of the participant became worse in 2007 compared to 2004. It is constructed using the responses to the same question as for variable HC069_better. Thus, those who chose option 3. Worse coverage, are classified as having worse coverage in 2007. HCO69

1 = worse coverage

Health insurance deductible Measured in euro
This variable contains the responses to the question that asked participants to mention the amount of their health insurance deductible. 


\section{Appendix 2}

Table A2.1. Multinominal Logistic Regression for Daily Smoking

\begin{tabular}{|c|c|c|c|c|c|c|c|c|c|}
\hline \multirow{3}{*}{ Explanatory variables } & \multicolumn{3}{|c|}{ Stop Daily Smoking in 2007} & \multicolumn{3}{|c|}{ Continue Daily Smoking in 2007} & \multicolumn{3}{|c|}{ Start Daily Smoking in 2007} \\
\hline & \multirow{2}{*}{ OR } & \multicolumn{2}{|c|}{$95 \% \mathrm{Cl}$} & \multirow{2}{*}{ OR } & \multicolumn{2}{|c|}{$95 \% \mathrm{Cl}$} & \multirow{2}{*}{ OR } & \multicolumn{2}{|c|}{$95 \% \mathrm{Cl}$} \\
\hline & & Lower & Upper & & Lower & Upper & & Lower & Upper \\
\hline Age $56-64$ & 1.09 & 0.60 & 2.00 & $0.70^{b}$ & 0.51 & 0.97 & 1.75 & 0.70 & 4.35 \\
\hline Age 65-74 & 0.54 & 0.25 & 1.15 & $0.37^{c}$ & 0.25 & 0.54 & 0.43 & 0.13 & 1.46 \\
\hline Age $\geq 75$ & $0.06^{c}$ & 0.01 & 0.50 & $0.23^{c}$ & 0.14 & 0.40 & 0.60 & 0.16 & 2.31 \\
\hline Gender & $0.57^{\mathrm{b}}$ & 0.33 & 0.97 & 0.80 & 0.61 & 1.05 & 1.30 & 0.62 & 2.71 \\
\hline Marital status & 2.06 & 0.79 & 5.37 & $0.63^{c}$ & 0.45 & 0.89 & 0.72 & 0.29 & 1.79 \\
\hline Change in marital status & 0.00 & 0.00 & 0.00 & 1.17 & 0.56 & 2.45 & 1.74 & 0.37 & 8.15 \\
\hline Education & 0.84 & 0.62 & 1.14 & $0.81^{\mathrm{b}}$ & 0.69 & 0.95 & 1.05 & 0.69 & 1.60 \\
\hline Annual $\mathrm{HH}$ gross income quintile & 1.04 & 0.82 & 1.33 & 0.98 & 0.86 & 1.11 & 0.75 & 0.53 & 1.08 \\
\hline Perceived health & 1.05 & 0.78 & 1.41 & $0.75^{c}$ & 0.64 & 0.88 & $0.57^{b}$ & 0.36 & 0.91 \\
\hline Better perceived health & 0.84 & 0.25 & 2.84 & $0.54^{\mathrm{b}}$ & 0.30 & 0.98 & 1.47 & 0.46 & 4.68 \\
\hline Worse perceived health & $3.30^{c}$ & 1.81 & 6.01 & 1.04 & 0.74 & 1.45 & 1.52 & 0.64 & 3.62 \\
\hline GALI & 0.59 & 0.27 & 1.32 & $0.72^{\mathrm{a}}$ & 0.49 & 1.06 & $0.22^{\mathrm{b}}$ & 0.06 & 0.85 \\
\hline Non-limited GALI & 1.81 & 0.75 & 4.39 & 0.88 & 0.55 & 1.41 & $6.71^{c}$ & 1.79 & 25.17 \\
\hline Limited GALI & 1.14 & 0.56 & 2.32 & 1.25 & 0.86 & 1.83 & $2.46^{a}$ & 0.98 & 6.18 \\
\hline Health insurance deductible & 1.09 & 0.85 & 1.40 & $0.88^{\mathrm{a}}$ & 0.76 & 1.02 & 1.12 & 0.78 & 1.59 \\
\hline Private insurance & $0.13^{\mathrm{b}}$ & 0.02 & 0.97 & $0.39^{b}$ & 0.16 & 0.94 & 0.28 & 0.03 & 2.42 \\
\hline Better health insurance coverage & $0.38^{\mathrm{a}}$ & 0.13 & 1.08 & $0.66^{\mathrm{a}}$ & 0.42 & 1.04 & $0.16^{a}$ & 0.02 & 1.25 \\
\hline Worse health insurance coverage & 0.98 & 0.40 & 2.41 & 0.82 & 0.49 & 1.37 & 0.27 & 0.04 & 2.06 \\
\hline \multicolumn{10}{|l|}{ Interaction } \\
\hline $\mathrm{HH}$ income quintile* Private insurance & 1.50 & 0.92 & 2.43 & $1.25^{\mathrm{a}}$ & 0.99 & 1.58 & 1.41 & 0.78 & 2.55 \\
\hline $\mathrm{N}$ (included in analysis) & 1533 & & & & & & & & \\
\hline
\end{tabular}

Abbreviation: GALI, Global Activity Limitation Index.

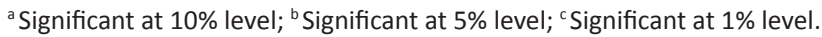

The base group for multinominal regression is those who are not daily smoker in 2004 and 2007 ; the age groups are compared to age $\leq 55$.

Table A2.2. Multinominal Logistic Regression for Excessive Alcohol Use

\begin{tabular}{|c|c|c|c|c|c|c|c|c|c|}
\hline \multirow{3}{*}{ Explanatory Variables } & \multicolumn{3}{|c|}{ Stop Excessive Alcohol Use } & \multicolumn{3}{|c|}{ Continue Excessive Alcohol Use } & \multicolumn{3}{|c|}{ Start Excessive Alcohol Use } \\
\hline & \multirow{2}{*}{ OR } & \multicolumn{2}{|c|}{$95 \% \mathrm{Cl}$} & \multirow{2}{*}{ OR } & \multicolumn{2}{|c|}{$95 \% \mathrm{Cl}$} & \multirow{2}{*}{ OR } & \multicolumn{2}{|c|}{$95 \% \mathrm{Cl}$} \\
\hline & & Lower & Upper & & Lower & Upper & & Lower & Upper \\
\hline Age $56-64$ & $1.47^{\mathrm{a}}$ & 0.98 & 2.21 & 1.24 & 0.73 & 2.11 & 1.54 & 0.75 & 3.19 \\
\hline Age $65-74$ & 1.02 & 0.62 & 1.67 & 1.02 & 0.55 & 1.89 & 0.95 & 0.40 & 2.28 \\
\hline Age $\geq 75$ & 0.67 & 0.34 & 1.33 & 0.54 & 0.23 & 1.29 & $0.24^{\mathrm{a}}$ & 0.05 & 1.14 \\
\hline Gender & $0.70^{\mathrm{b}}$ & 0.50 & 0.99 & $0.31^{\mathrm{c}}$ & 0.19 & 0.50 & $0.33^{c}$ & 0.17 & 0.63 \\
\hline Marital status & 1.09 & 0.67 & 1.77 & 1.44 & 0.75 & 2.77 & $0.54^{\mathrm{a}}$ & 0.26 & 1.11 \\
\hline Change in marital status & 0.76 & 0.26 & 2.20 & 0.00 & 0.00 & 0.00 & 0.67 & 0.08 & 5.35 \\
\hline Education & 1.15 & 0.94 & 1.40 & 1.11 & 0.87 & 1.43 & $1.37^{\mathrm{a}}$ & 0.96 & 1.94 \\
\hline Annual HH gross income quintile & 1.10 & 0.93 & 1.30 & 1.05 & 0.84 & 1.31 & 0.92 & 0.68 & 1.26 \\
\hline Perceived health & $1.19^{\mathrm{a}}$ & 0.99 & 1.44 & 0.94 & 0.73 & 1.21 & 0.96 & 0.68 & 1.36 \\
\hline Better perceived health & 0.78 & 0.38 & 1.63 & 1.09 & 0.47 & 2.53 & 0.90 & 0.26 & 3.11 \\
\hline Worse perceived health & 1.20 & 0.79 & 1.83 & 0.88 & 0.51 & 1.53 & 1.47 & 0.71 & 3.02 \\
\hline GALI & 0.94 & 0.56 & 1.55 & 1.07 & 0.56 & 2.02 & 0.77 & 0.32 & 1.88 \\
\hline Non-limited GALI & 1.07 & 0.59 & 1.94 & 1.17 & 0.57 & 2.40 & 1.45 & 0.52 & 4.00 \\
\hline Limited GALI & $1.60^{\mathrm{b}}$ & 1.02 & 2.50 & $1.88^{b}$ & 1.06 & 3.34 & 1.28 & 0.56 & 2.94 \\
\hline Health insurance deductible & 1.06 & 0.91 & 1.25 & 0.99 & 0.80 & 1.22 & 1.02 & 0.77 & 1.35 \\
\hline Private insurance & $0.23^{b}$ & 0.07 & 0.73 & 1.24 & 0.37 & 4.18 & 0.52 & 0.09 & 3.05 \\
\hline Better health insurance coverage & 1.04 & 0.64 & 1.69 & $0.43^{a}$ & 0.18 & 1.02 & 1.17 & 0.50 & 2.75 \\
\hline Worse health insurance coverage & 0.66 & 0.32 & 1.35 & $1.80^{\mathrm{a}}$ & 0.93 & 3.51 & 1.59 & 0.60 & 4.25 \\
\hline \multicolumn{10}{|l|}{ Interaction } \\
\hline $\mathrm{HH}$ income quintile* Private insurance & $1.48^{c}$ & 1.11 & 1.97 & 1.04 & 0.75 & 1.45 & 1.24 & 0.77 & 2.01 \\
\hline $\mathrm{N}$ (included in analysis) & 1533 & & & & & & & & \\
\hline
\end{tabular}

Abbreviation: GALI, Global Activity Limitation Index.

a Significant at $10 \%$ level; ${ }^{b}$ Significant at $5 \%$ level; ' Significant at $1 \%$ level.

The base group for multinominal regression is those who are not excessive alcohol users in 2004 and 2007, Age groups are compared to age $\leq 55$. 
Table A2.3. Multinominal Logistic Regression For Physical Inactivity

\begin{tabular}{|c|c|c|c|c|c|c|c|c|c|}
\hline \multirow{3}{*}{ Explanatory Variables } & \multicolumn{3}{|c|}{ Stop Physical Inactivity } & \multicolumn{3}{|c|}{ Continue Physical Inactivity } & \multicolumn{3}{|c|}{ Start Physical Inactivity } \\
\hline & \multirow{2}{*}{ OR } & \multicolumn{2}{|c|}{$95 \% \mathrm{Cl}$} & \multirow{2}{*}{ OR } & \multicolumn{2}{|c|}{$95 \% \mathrm{Cl}$} & \multirow{2}{*}{ OR } & \multicolumn{2}{|c|}{$95 \% \mathrm{Cl}$} \\
\hline & & Lower & Upper & & Lower & Upper & & Lower & Upper \\
\hline Age 56-64 & 0.76 & 0.26 & 2.28 & 2.22 & 0.44 & 11.29 & 1.21 & 0.58 & 2.53 \\
\hline Age 65-74 & $2.32^{\mathrm{a}}$ & 0.86 & 6.26 & 1.69 & 0.28 & 10.06 & 1.61 & 0.75 & 3.44 \\
\hline Age $\geq 75$ & $4.81^{c}$ & 1.62 & 14.28 & $6.63^{b}$ & 1.25 & 35.21 & $2.97^{c}$ & 1.30 & 6.76 \\
\hline Gender & $1.84^{\mathrm{a}}$ & 0.89 & 3.80 & 1.47 & 0.58 & 3.69 & $1.73^{\mathrm{b}}$ & 1.04 & 2.89 \\
\hline Marital status & 1.66 & 0.69 & 3.98 & 0.70 & 0.26 & 1.91 & 1.32 & 0.71 & 2.47 \\
\hline Change in marital status & 2.21 & 0.57 & 8.56 & 2.02 & 0.23 & 18.09 & 2.14 & 0.79 & 5.76 \\
\hline Education & 1.06 & 0.70 & 1.61 & 0.85 & 0.50 & 1.45 & $0.65^{c}$ & 0.48 & 0.88 \\
\hline Annual $\mathrm{HH}$ gross income quintile & 1.01 & 0.73 & 1.39 & 1.06 & 0.67 & 1.66 & 0.98 & 0.77 & 1.26 \\
\hline Perceived health & $0.33^{c}$ & 0.20 & 0.53 & $0.32^{c}$ & 0.17 & 0.63 & $0.53^{c}$ & 0.38 & 0.73 \\
\hline Better perceived health & 1.47 & 0.46 & 4.66 & 0.00 & 0.00 & 0.00 & 0.51 & 0.12 & 2.19 \\
\hline Worse perceived health & 0.73 & 0.33 & 1.60 & $3.02^{b}$ & 1.09 & 8.39 & $1.99^{c}$ & 1.19 & 3.32 \\
\hline GALI & 0.95 & 0.36 & 2.47 & 1.41 & 0.31 & 6.34 & 1.84 & 0.84 & 4.05 \\
\hline Non-limited GALI & 0.47 & 0.15 & 1.50 & 0.29 & 0.03 & 2.39 & 0.65 & 0.29 & 1.46 \\
\hline Limited GALI & 1.14 & 0.39 & 3.32 & 1.29 & 0.24 & 6.94 & $3.11^{c}$ & 1.45 & 6.66 \\
\hline Health insurance deductible & 0.75 & 0.46 & 1.24 & 1.06 & 0.64 & 1.76 & 0.93 & 0.70 & 1.25 \\
\hline Private insurance & 2.33 & 0.35 & 15.43 & 2.71 & 0.24 & 30.90 & 1.46 & 0.38 & 5.54 \\
\hline Better health insurance coverage & 1.77 & 0.63 & 4.94 & 0.43 & 0.05 & 3.46 & 0.90 & 0.40 & 2.01 \\
\hline Worse health insurance coverage & 0.79 & 0.21 & 2.89 & 0.00 & 0.00 & 0.00 & $0.33^{\mathrm{a}}$ & 0.10 & 1.13 \\
\hline \multicolumn{10}{|l|}{ Interaction } \\
\hline $\mathrm{HH}$ income quintile* Private insurance & 0.77 & 0.43 & 1.36 & 0.84 & 0.40 & 1.77 & 1.09 & 0.74 & 1.61 \\
\hline $\mathrm{N}$ (included in analysis) & 1533 & & & & & & & & \\
\hline
\end{tabular}

Abbreviation: GALI, Global Activity Limitation Index.

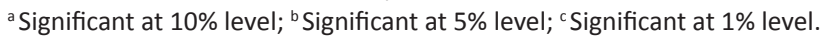

The base group for multinominal regression is those who are not physically inactive in 2004 and 2007 ; the age groups are compared to age $\leq 55$. 